\title{
The Role Of End-User Training In Technology Acceptance
}

Bryan Marshall, Georgia College and State University

Robert Mills, Utah State University

David Olsen, Utah State University

\begin{abstract}
The purpose of this paper is to examine the role end-user training has on performance expectancy and effort expectancy, two variables associated with technology acceptance. The technologybased elements of the HIPAA security rules among oral surgeons were used for the study. The method of the investigation was a cross-sectional correlational study using a self-reported mailed questionnaire. The survey was created using preexisting scales from the Unified Theory of Acceptance and Use of Technology. Results suggest end-user training is positively correlated with both performance expectancy and effort expectancy.
\end{abstract}

Keywords: End-User Training, IS Survey Research, Technology Acceptance, Unified Theory of Acceptance and Use of Technology, Health Care, HIPAA

\section{INTRODUCTION}

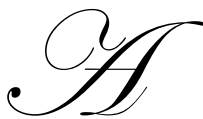

dvances in systems, powerful software suites, and data management have increased the amount of end-user computing required by accountants (16), and presumably other professionals, particularly in generating and analyzing reports. Emerging areas such as information security and business intelligence have also increased the need of end-users to adopt new technologies. End-users often receive training in an effort to make adoption and implementation of new systems possible. Unfortunately, the role of end-user training and technology acceptance is not well documented.

The purpose of this research is to examine the impact end-user training has on technology acceptance. As companies continue to rely on end-user training to improve productivity and gain competitive advantage, the impact of end-user training on the acceptance of new technologies must be examined. Technology acceptance theory has played a key role in the examination of user behavior toward the acceptance of new technologies. Technology acceptance theory identifies different models, frameworks, and theories, which have been used to discover the factors or constructs influencing the acceptance and use of technology. Several research studies have demonstrated that a variety of factors influence the rate of acceptance of new technologies when new systems are implemented (5). Prior research also suggests that small organizations encounter unique challenges when attempting to adopt a new technology $(11,12)$.

Research studies within the domain of technology acceptance has included end-user training as a significant contributing factor that influences users' behavior toward the acceptance of technology $(5,7,18,19)$. However, the research findings concerning the role, importance, and utility of end-user training are ambiguous. A better understanding of the determinants of perceived usefulness would enable those responsible for implementing new systems to design organizational interventions that would increase user acceptance and usage of new systems (22). 


\section{Background On UTAUT}

In 2003 Venkatesh, Davis, Davis, and Morris presented a theory which synthesized previous research in technology acceptance and is known as the Unified Theory of Acceptance and Use of Technology (UTAUT). The UTAUT model integrated eight of the prominent user behavior models and included the (a) Theory of Reasoned Action (TRA), (b) Technology Acceptance Model (TAM), (c) Motivational Model (MM), (d) Theory of Planned Behavior (TPB), (e) Combined TAM and TPB (C-TAM-TPB), (f) Model of PC Utilization (MPCU), (g) Innovation Diffusion Theory (IDT), and (h) Social Cognitive Theory (SCT).

The UTAUT model included several objectives: (a) to review user acceptance research, (b) to compare the eight models, (c) to formulate the UTAUT model, and (d) to empirically validate the UTAUT model. Most of the related UTAUT studies used university students as the participants. In addition, the reviewed studies examined looking at technologies that were voluntarily adopted (23). Venkatesh et al. found 32 constructs across the eight models and they also found four "moderating" variables, concluding that few studies have been done that look at complex "managerial" information technologies.

The UTAUT model has four main independent variables: performance expectancy, effort expectancy, facilitating conditions, and social influence (see Appendix 1). The first independent variable performance expectancy is defined as the degree to which an individual believes that using the system will help one to attain gains in job performance (23). Second, effort expectancy is defined as the "degree of ease associated with the use of the system" (23). Third, facilitating conditions is defined as the "degree to which an individual believes that an organizational and technical infrastructure exists to support use of the system" (23). Finally, social influence is defined as the "degree to which an individual believes that important others believe he or she should use the system" (23).

There were four main moderating variables also defined in the literature. Of these, experience is defined as the amount of experience that a person has in a specific domain. Previous research has shown that as experience increases, effort expectancy will decrease, or in other words, the system will be easier to use $(1,2,6,20,21)$. The survey also included three other variables that the UTAUT measure addresses, but the variables were found to be insignificant: (a) attitude toward the technology, (b) anxiety, and (c) self-efficacy.

\section{End-User Training}

Companies increasingly use end-user training to help create a more productive and competitive workforce. Anne Fisher's 2005 Fortune article identifies the profession of training \& development specialists as one of the 20 fastest-growing professional jobs over the next ten years (8). While constructs such as performance expectancy and effort expectancy are critical factors in actual implementation behavior of technology acceptance, an equally important question is how an organization can specifically impact the level of performance expectancy and effort expectancy. Performance expectancy is related to how useful the system is perceived to be while effort expectancy is associated with how easy the system is to use (23). End-user training programs are often designed to specifically address issues of usefulness and ease of use.

Malcolm Knowles' classic Theory of Andragogy (13) includes four principles related to training adult learners. These principles include:

1. Adults need to be involved in the planning and evaluation of their instruction.

2. Experience (including mistakes) provides the basis for learning activities.

3. Adults are most interested in learning about topics that have immediate relevance to their job or personal life.

4. Adult learning is problem-centered rather than content-oriented.

Although Knowles doesn't specifically use the constructs "perceived usefulness" and "perceived ease of use", there is clearly a logical connection between principles of andragogy and technology acceptance. 
Because end-user training programs are often problem-centered, individuals receiving training are likely to find technology systems easier to use. Additionally, programs that implement andragogy principles such as addressing the immediate relevance to job performance are more likely to increase individuals' perception of the usefulness of the system than those who did not receive training. The evaluation of e-learning and end-user training programs often examines both usefulness and ease of use as part of the assessment process. For instance, Cappell and Hayen (4) specifically include both ease of use and usefulness as specific elements of their learning unit assessment for evaluating e-learning. Based on past experience, the authors posit end-user training programs will positively correlate with both performance and effort expectancy.

\section{HYPOTHESES}

H1: End-user training will positively correlate with performance expectancy.

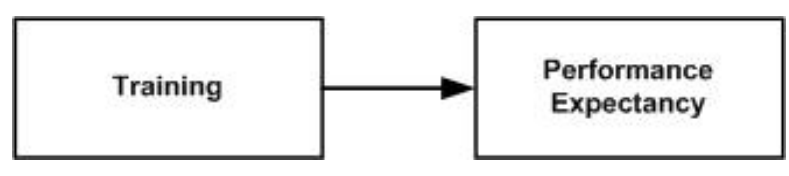

Figure 1: Hypothesis 1

H2: End-user training will positively correlate with effort expectancy.

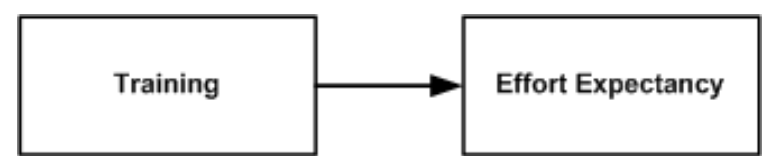

Figure 2: Hypothesis 2

\section{METHOD}

This section describes a description of the population, sample selection, power analysis, and details related to the development and administration of the survey instrument. The HIPAA Security Rule was chosen as the application of the theory for this study. The HIPAA Security Rule came into effect in March of 2005 and requires medical practices to secure electronic patient data. The HIPAA Security Rule was chosen because of its importance to the medical profession, specifically to small medical practices.

\section{Research Population}

The American Association of Oral and Maxillofacial Surgeons (AAOMS) is the nonprofit professional organization serving oral surgeons. According to AAOMS, approximately 90 percent of all oral surgeons belong to its organization. As a service to its members, AAOMS currently posts the names, city, state, and zipcode of 5,472 oral surgeons on the AAOMS home page (3). Each state was accessed separately in order to gather the population to be sampled, and the oral surgeons from each state were copied into an Excel spreadsheet along with a street address, city, state, zipcode, and phone number.

\section{Power Analysis}

A power analysis was completed to estimate the required number of respondents in this study. Power analysis software was used to determine that 200 participants would be sufficient to run a correlation matrix on the hypothesized models. Assuming a 20 percent survey return rate, a sample of 1,000 randomly selected medical practices was chosen to achieve the 200 estimated participants. 


\section{Instrument Development}

The HIPAA Security Rule contains 37 different policies and procedures, mandating the use of many different technologies. Due to the nature of technology acceptance research, application of the theory to multiple technologies within the same study is not practical $(5,14)$. For this reason the 37 different policies were broken down into separate categories of "technical" and "non-technical", and only technical categories were considered for this study. The survey was created using preexisting scales from the Unified Theory of Acceptance and Use of Technology (UTAUT). Rewording the scales in a way to apply the theory to different domains is common practice in technology acceptance research $(5,15,1)$. In this instance, the survey questions were applied to the HIPAA Security Rule policy on mandatory use of electronic data backup systems in medical practices.

\section{Survey Administration}

According to the HIPAA Security Rule, each medical practice must designate a compliance officer to maintain the medical office records. Each of these compliance officers was contacted and asked to complete the survey. The office manager or practicing physician was asked to complete the survey if no compliance officer had been identified.

\section{RESULTS}

This section presents the results of the study by providing a description of the respondents, internal reliability of the measures, and concludes with a presentation of the correlation matrix.

\section{Description Of Respondents}

Out of the 1,000 surveys sent out, 208 were received at the time of this analysis. The overall demographics of the respondents are presented in Appendix 3. With respect to gender of the respondents, 106 (51\%) were female and $94(45 \%)$ were male, with 8 practices not reporting gender $(4 \%)$. The primary age group of the respondents was between 41 and $60(65 \%)$. The cover letter which was sent with the survey to the medical practices asked the doctor to have the HIPAA compliance officer or office manager fill out the short survey. The largest percentage of respondents $(42 \%)$ indicated they had received equal to or higher than a doctorate degree. Only 3 percent of the medical practices reported not using computers in the office. Conversely, 70 percent of the offices reported using computers for over 10 years. Additionally, 82 percent reported using computers since the year 2000 .

The dependent variable "actual implementation behavior" was analyzed using descriptive statistics. The frequency of usage showed that over 80 percent of all practices backup their patient data at least daily ( 5 times a week). Over 92 percent of the practices report backing up their data at least once a week.

\section{Internal Reliability of the Measures}

Cronbach's alpha was used to assess the reliability of the measure used in this study. The coefficient reported in Cronbach's alpha usually range from 0 to 1 . All of the items were tested to determine the constructs Cronbach's alpha. As seen in Table 1, each construct had an alpha over .65. This high reliability was expected because the questions were based on existing scales $(14,17)$.

Table 1: Cronbach's Alpha Reliability Test

\begin{tabular}{|c|c|c|}
\hline Construct & Number of Items & Cronbach's Alpha \\
\hline Training and Resources & 3 & 0.913 \\
\hline Performance Expectancy & 2 & 0.697 \\
\hline Effort Expectancy & 2 & 0.929 \\
\hline
\end{tabular}




\section{Correlation Matrix}

A correlation matrix is a table of the different constructs and how they correlate with each other (16). Table 2 presents the descriptive statistics for each variable, including mean and standard deviation, and the correlation between the variables with the significance level. The significance of each correlation was evaluated at the twotailed test level. The results of the correlation matrix in Table 2 revealed that the UTAUT factors (training, performance, and effort) were all strongly correlated.

Table 2: Correlation Matrix

\begin{tabular}{|c|c|c|c|c|c|}
\hline Variables & Training & $\begin{array}{c}\text { Performance } \\
\text { Expectancy }\end{array}$ & $\begin{array}{c}\text { Effort } \\
\text { Expectancy }\end{array}$ & Usage (Yes/No) & $\begin{array}{c}\text { Usage (Number } \\
\text { of Times) }\end{array}$ \\
\hline Standard Deviation & 1.130 & 1.160 & 1.160 & 0.240 & 2.150 \\
\hline Mean & 4.270 & 4.150 & 4.270 & 0.940 & 5.080 \\
\hline $\begin{array}{c}\text { Usage } \\
\text { (Number Times) } \\
\end{array}$ & & & & & 1.000 \\
\hline Usage (Yes/No) & & & & 1.000 & $0.618^{*}$ \\
\hline Effort & & & 1.000 & $0.541 *$ & $0.305^{*}$ \\
\hline Performance & & 1.000 & $0.776^{*}$ & $0.569 *$ & $0.361 *$ \\
\hline Training & 1.000 & $0.769 *$ & $0.840 *$ & $0.567 *$ & $0.372 *$ \\
\hline
\end{tabular}

Training correlated with performance (.789) and effort (.840), all of which were significant at the .01 level. Performance correlated with effort (.776) significant at the .01 level. In this study the two dependent variables (usage and how many times) were significantly correlated (.618) at the .01 level. To further support previous research (23), each of the constructs from the UTAUT model (training, performance, and effort) were significantly correlated with the actual implementation behavior (usage) at the .01 level.

\section{DISCUSSION}

The purpose of this research was to examine the impact of end-user training on technology acceptance theory to determine how to improve the implementation and adoption of technologies mandated by the federal government. Two hypotheses (Appendix 2) were tested and supported in this study using a correlation matrix. Training was positively correlated with both performance expectancy and effort expectancy. End-user training appears to be an important and understudied factor in technology acceptance. End-user training programs could be specifically designed to improve performance expectancy and effort expectancy to aid in the acceptance of new technologies in organizations.

\section{SUGGESTIONS FOR FUTURE RESEARCH}

Future research is needed in several areas related to this research. First, additional research should be conducted to determine the mediating and moderating effects among elements such as end-user training and technology acceptance factors. In addition, we believe that specific research to determine which training models, components, and principles have the greatest impact on performance expectancy and effort expectancy will be valuable.

Additional research is also necessary to examine specific instructional design prescriptions used for creating end-user training programs have the greatest impact on technology acceptance. With the growing complexities of computer applications and the increasing diversity of end users, the importance of researching the impact of specific end-user training designs on technology acceptance is critical (10). Further, individual characteristics of the trainees also impact the role of end-user training programs and warrants further investigation. Prior research suggests anxieties related to communication and computing have a direct influence on an individual's interaction with technology tools used in an e-Learning environment $(9,24)$. More research is necessary to 
determine what impact these individual characteristics have on end-user training, and ultimately on technology acceptance.

Taking advantage of end-user training programs to assist in the adoption of technology appears to be a valuable, but understudied research area. By better understanding the impact training has on technology acceptance, organizations will be better prepared to design programs specifically geared toward improving both performance expectancy and effort expectancy, and ultimately improving the organizations acceptance of technology.

\section{REFERENCES}

1. Agarwal, R., and Prasad, J. The Role of Innovation Characteristics and Perceived Voluntariness in the Acceptance of Information Technologies, Decision Sciences, (28:3), 1997, pp. 557-582.

2. Agarwal, R., and Prasad, J. A Conceptual and Operational Definition of Personal Innovativeness in the Domain of Information Technology, Information Systems Research, (9:2), 1998, pp. 204-215.

3. American Association of Oral Maxillofacial Surgeons (AAOMS). About AAOMS, Online, retrieved on 4/1/2005 from http://www.aaoms.org/aboutus.cfm.

4. Cappel, J. J. and Hayen, R. L. Evaluating E-Learning: A Case Study, Journal of Computer Information Systems, (44:4), 2004, pp. 49-56.

5. Davis, F. D. Perceived Usefulness, Perceived Ease of Use, and User Acceptance of Information Technology, MIS Quarterly, (13:3), 1989, pp. 319-340.

6. Davis, F. D., Bagozzi, R. P., and Warshaw, P. R. User Acceptance of Computer Technology: A Comparison of Two Theoretical Models, Management Science, (35:8), 1989, pp. 982-1003.

7. Davis, S. A. Training End Users: An Experimental Investigation of Roles of the Computer Interface and Training Methods, MIS Quarterly, (17:1), 1993, pp. 61-85.

8. $\quad$ Fisher, A. Hot Careers for the Next 10 Years, Fortune, March 21, 2005, pp 131.

9. Fuller, R. M, Vician, C., and Brown, S. A. E-Learning and Individual Characteristics: The Role of Computer Anxiety and Communication Apprehension, Journal of Computer Information Systems, (46:4), 2006, pp. 103-115.

10. Hasan, B. and Ali, J. M. H. An Empirical Examination of a Model of Computer Learning Performance, Journal of Computer Information Systems, (44:4), 2004, pp. 27-33.

11. Lee, J. Discriminant Analysis of Technology Adoption Behavior: A Case of Internet Technologies in Small Businesses, Journal of Computer Information Systems, (44:4), 2004, pp. 57-66.

12. Lee, J. and Runge, J. Adoption of Information Technology in Small Business: Testing Drivers of Adoption for Entrepreneurs, Journal of Computer Information Systems, (42:1), 2001, pp. 44-57.

13. Knowles, M. The Adult Learner: A Neglected Species (3rd Ed.), Gulf Publishing, Houston, TX, 1984.

14. Ma, Q., and Liu, L. The Technology Acceptance Model: A Meta-Analysis of Empirical Findings, Journal of Organizational and End User Computing, (16:1), 2004, pp. 59-72.

15. Morris, M. G., and Dillon, A. The Influence of User Perceptions on Software Utilization: Application and Evaluation of A Theoretical Model of Technology Acceptance, IEEE Software, (14:4), 1997, pp. 58-75.

16. Paquette, L. R. Problem Based Learning In the AIS Course, The Review of Business Information Systems, (7:2), 2003, pp 59-72.

17. Pedhazur, E. J., and Schmelkin, L. P. Measurement, Design, and Analysis: An Integrated Approach, Lawrence Erlbaum Associates, Hillsdale, New Jersey, 1991.

18. Riemenschneider, C. K. and McKinney, V. R. Assessing Belief Differences in Small Business Adopters and Non-Adopters of Web-Based E-Commerce, Journal of Computer Information Systems, (42:2), 2001, pp. 101-108.

19. Riemenschneider, C. K. and Hardgrave, B. C. Explaining Software Development Tool Use with the Technology Acceptance Model, Journal of Computer Information Systems, (41:4), 2001, pp. 1-8.

20. Thompson, R. L., Higgins, C. A., and Howell, J. M. Personal Computing: Toward A Conceptual Model of Utilization, MIS Quarterly, (15:1), 1991, pp. 131.

21. Thompson, R. L., Higgins, C. A., and Howell, J. M. Influence of Experience on Personal Computer Utilization: Testing A Conceptual Model, Journal of Management Information Systems, (11:1), 1994, pp. 167-187. 
22. Venkatesh, V. Creating an Effective Training Environment for Enhancing Telework, Int. J. HumanComputer Studies, (52), 2000, pp. 991-1005.

23. Venkatesh, V., Morris, M. G., Davis, G. B., and Davis, F. D. User Acceptance of Information Technology: Toward A Unified View, MIS Quarterly, (27:3), 2003, pp. 425-478.

24. Vician, C, and Davis, L. R. Investigating Computer Anxiety and Communication Apprehension as Performance Antecedents in a Computing-Intensive Learning Environment. Journal of Computer Information Systems, (43:2), 2002-2003, 51-57.

\section{APPENDICES}

Appendix 1: Unified Theory of Acceptance and Use of Technology.

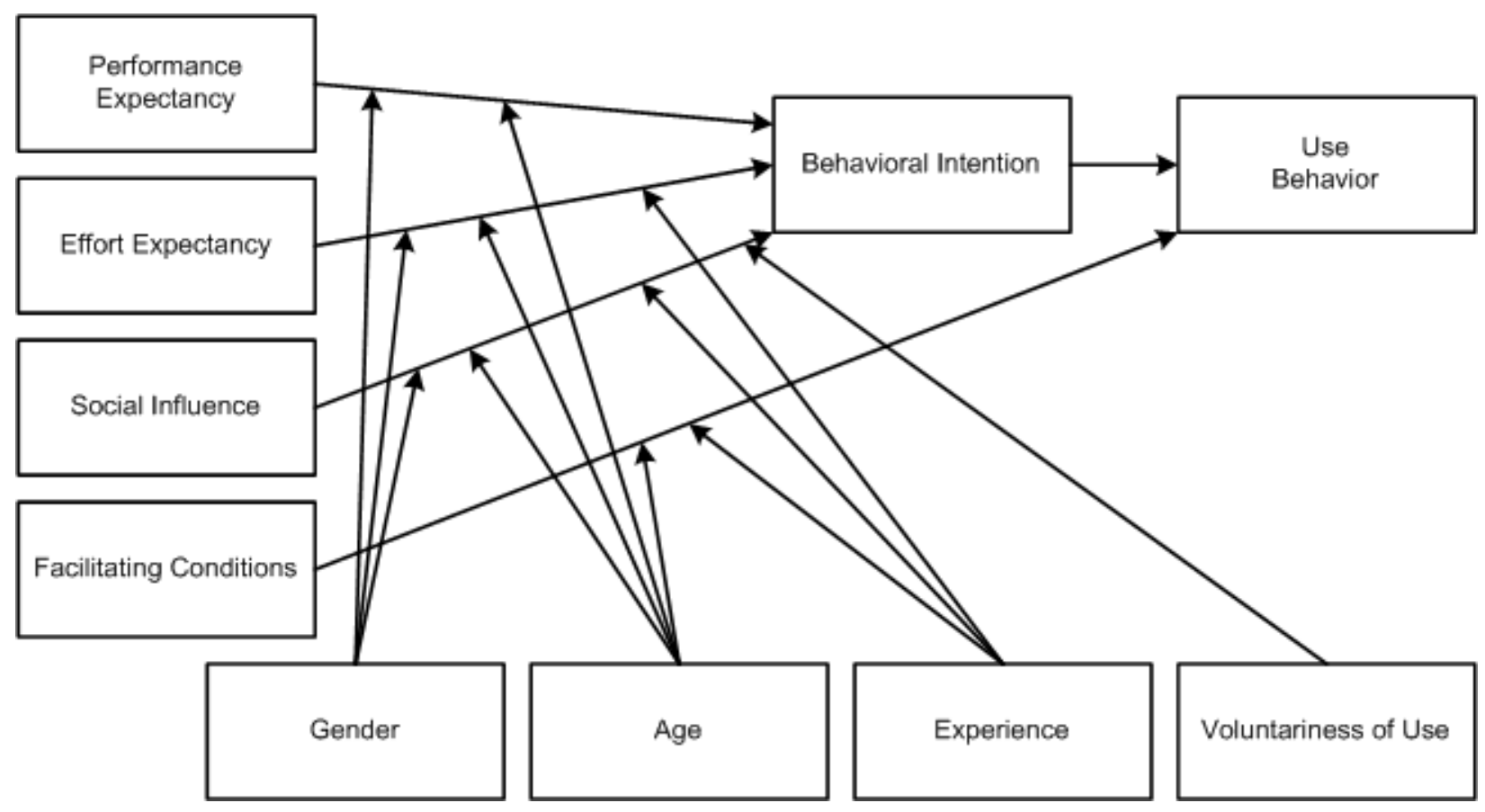

Appendix 2: Hypothesis description.

\begin{tabular}{|c|l|c|}
\hline Hypothesis \# & \multicolumn{1}{|c|}{ Description } & Results \\
\hline H1 & End-User Training will positively correlate with Performance expectancy. & Supported \\
\hline H2 & End-User Training will positively correlate with Effort expectancy. & Supported \\
\hline
\end{tabular}




\section{Appendix 3: Description Of Respondents.}

\begin{tabular}{|c|c|c|}
\hline Characteristics & Frequency & Percent (\%) \\
\hline \multicolumn{3}{|l|}{ Gender } \\
\hline Male & 94 & 45.19 \\
\hline Female & 106 & 50.96 \\
\hline Unknown & 8 & 3.85 \\
\hline \multicolumn{3}{|l|}{ Age } \\
\hline Under 24 & 2 & 0.96 \\
\hline $25-30$ & 11 & 5.29 \\
\hline $31-35$ & 13 & 6.25 \\
\hline $36-40$ & 23 & 11.06 \\
\hline $41-45$ & 39 & 18.75 \\
\hline $46-50$ & 35 & 16.83 \\
\hline $51-55$ & 30 & 14.42 \\
\hline $56-60$ & 32 & 15.38 \\
\hline $61-65$ & 8 & 3.85 \\
\hline Over 66 & 2 & 0.96 \\
\hline Unknown & 13 & 6.25 \\
\hline \multicolumn{3}{|l|}{ Education } \\
\hline High School & 28 & 13.46 \\
\hline Associates Degree & 32 & 15.38 \\
\hline Bachelor Degree & 26 & 12.50 \\
\hline Master Degree & 14 & 6.73 \\
\hline Doctorate Degree & 87 & 41.83 \\
\hline Unknown & 21 & 10.10 \\
\hline \multicolumn{3}{|l|}{ Computer Experience } \\
\hline Under 1 Year & 7 & 3.37 \\
\hline $1-5$ Years & 25 & 12.02 \\
\hline 6-10 Years & 60 & 28.85 \\
\hline 11-15 Years & 73 & 35.10 \\
\hline Over 15 Years & 38 & 18.27 \\
\hline Unknown & 5 & 2.40 \\
\hline
\end{tabular}

